\title{
Prevalence of Primary School Dropout in Bale Zone Pastoralists of Oromia Region, Southeastern Ethiopia
}

\author{
Teshome Sirak, Gamachu Gishe \\ Department of Psychology, School of Behavioral Science, Madda Walabu University, Bale Robe, Ethiopia \\ Email: teshomesirak@gmail.com
}

Received 7 March 2016; accepted 21 March 2016; published 24 March 2016

Copyright (C) 2016 by authors and OALib.

This work is licensed under the Creative Commons Attribution International License (CC BY). http://creativecommons.org/licenses/by/4.0/

(c) (7) Open Access

\begin{abstract}
Primary school dropout in the area of pastoralists is a complex issue in Ethiopia particularly in Oromia Region, Bale Zone. However, the problem has not been addressed yet. Thus, this study is conducted with the aim to assess the prevalence of primary school dropout in Bale Zone of Oromia Region, Southeastern Ethiopia. Cross-sectional research design was used to attain the objective of the research. School principals, supervisors, members of parent teacher association and Kebele education and training board, woredas and zonal education office heads were participated in this study. Varity of data collection tools were employed namely, interview, focus group discussion guide and document analysis. The analysis was made both quantitatively and qualitatively as per the nature of the data. The results show that the overall dropout rate was $13 \%$. More specifically, the highest dropout rate was found in grade seven for boys and in grade five for girls. In the schools which have food support the rate was low and vise versa. Out of the four woredas of the study area the rate was high in Sewena.
\end{abstract}

\section{Keywords}

Prevalence, Primary School, Dropouts, Pastoralists

Subject Areas: Education

\section{Introduction}

Dropping out of school is an obviously powerful risk factor for exclusion, especially since most children that dropout do not return [1]. It is a very serious problem because it affects the dropouts, parents, government and the society [2]. Research on schools in developing countries revealed that high dropout rates lead to a significant waste of resources in many school systems [3]. In Burkina Faso, Ethiopia, Kenya, Mali and Mozambique, more 
than $80 \%$ of rural children who had left primary school dropped out [4]. As study conducted in five regions of Ethiopia shows, primary school dropout rates in 1999/00 almost doubled in 2003/04 from 9 percent to 19 percent [5]. Thus, high dropout rate is a major obstacle in the achievement of universal primary education. This is because when students leave the school, there is wastage of resources in one way and they occupied a school space which could be used for the other new comers in the other way. Beside this, they have not acquired the minimum level of literacy and numeracy skills [6].

In Ethiopia 15.7\% (boys 15.9 and girls 15.4) children have left the school before completing primary school education in the year 2012/13 [7]. The target set by the government concerning primary school dropout was 8 percent for the year 2010/11, despite the fact that actual dropout rate was 13 percent [8]. The data show that the rate is higher for grade 1 , grade 5 , and grade 8 whereas the lowest dropout rate is registered at grade 3 . Furthermore, as it was indicated in the ministry document the rate escalate to $18.6 \%$ for both sexes in Oromia Regional State [7]. Moreover, [9] found that girls were less likely to enrolled primary school than boys. In addition, the probability of completing primary school was affected more negatively for girls (40.3\%) than for boys (31.9\%).

As to recent study, the dropout rates were increasing in an alarming condition especially in some region and pastoralists area. For example, in Harari Region students dropout rates were increased year by year and great percent of students dropped out and very great percent of students were at risk of dropping out of their education [10]. Similarly, [6] report revealed that the total primary school dropout rate of Bale Zone was 18 (boys 19 and girls 16.8) in the year 2011/12. However, according to [11] report, in 2012/13 academic year the primary schools rate was reduced to 5.62 (boys 5.70 and girls 5.49) in pastoralist area of Zone.

Moreover, let's regard the issue number of researches having conducted in Borana pastoralists of Oromia Region and other parts of Ethiopia. However, to the knowledge of these researchers, no researches have been conducted concerning primary school dropout in Bale pastoralist. Thus, this study intended to assess the prevalence of primary school dropout in Bale Zone of Oromia Region, Southeastern Ethiopia.

\section{Methodology}

Cross-sectional research design was employed in this study to assess the prevalence of school dropout. The study was focused on sixteen primary schools (grade 1 - 8) randomly selected from the four woredas (districts). Besides, 48 parents ( 3 parents from each school) of dropout were selected via quota sampling. On the other hand, school principals, parent teacher association, and kebeles education and training board of each school and 8 supervisors, each woredas education officials and head of zonal education office were purposely selected.

With regard to data gathering instruments, semi-structured interview guide which was adapted from [12] used to collect data from supervisors, school principals, Zonal and woredas Education offices officials. In addition, focus group discussion was made with parents of dropouts, parent teacher association, kebele education and training board. Document analysis regarding prevalence of school dropout was also employed. During focus group discussion and interview Afan Oromo language was used to avoid the distortion of information. Finally, the data were collected after informed consents made with the participants. Quantitative data gathered through document analysis were analyzed using descriptive statistics such as mean, frequency and percentage. On the other hand, qualitative data were analyzed by coding, identifying common themes and categorizing of the themes.

\section{Results}

As it can be seen from Figure 1, the total percentage of the first grade in all 16 primary schools males' dropout rates were $17.55 \%$, which is the second highest rate. On the other hand, grade one female rate of school dropping was $13.73 \%$. According to the majority of participants, number of grade one students dropout school mainly because of two reasons. First, the students are not physically strong enough to walk the long distance to school on foot. Second, these children always move from place to place with their family while their families migrate from one place to the other due to the mobile nature of pastoralists. If we take the male dropout rate at grade two, a bit down to $16.90 \%$. On the other hand, females' dropout rate was reduced to $11.03 \%$. In the case of grade three males' dropout rate, it was reduced by $3.78 \%$, but that of females was almost remain the same, i.e. reduced by $0.54 \%$. Regarding grade four males' rate of school dropping, it was increased by less than $1 \%$. In contrast to this, that of females' was reduced by $3.58 \%$. The male students' dropout rate at fifth grade level was raised to $16.84 \%$ when compared to grade four students' dropout rate. Furthermore, the rate of females dropped 


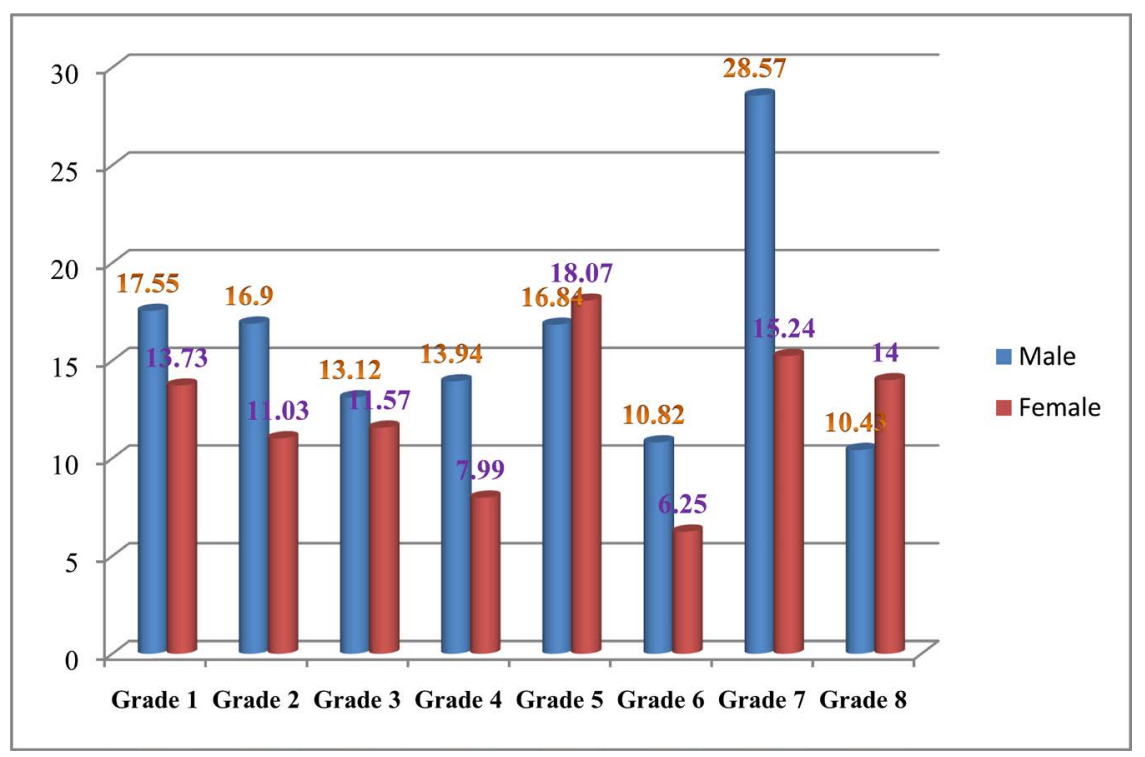

Figure 1. Prevalence of primary school dropout rate by grade level and sex in percent.

was much more increased to $18.07 \%$, which is the highest rate of all. Similarly, the key informants from all study areas reported that the female students of pastoralists consider second cycle primary school (grade 5 - 8) as the peak of their education. Participants also elaborated that there are various problems related to traditional practices. For instance, upon reaching marriageable ages the female students have no choice but get married when a man proposes a marriage contract. Even if these female students may be in grade 4 or 5 they have to stop their education and get married if the chance present itself.

Moreover, according to one school principal in Sawena Woreda, the concrete case regarding female students' status in his school shows there were about 22 female students enrolled in grade five. The numbers of female students were reduced to 17,3 , and 1 in grade six, seven and eight respectively. On the other hand, the above Figure 1 shows that grade six male students dropout rate was decreased to $10.82 \%$. Moreover, at six grade level, females' dropout rate was radically reduced to $6.25 \%$. Contrary to all grade levels, grade seven dropout rate of male was much more increased to $28.57 \%$. Whereas, the rate of female in grade seven was raised to $15.24 \%$. This shows that, males' dropout rate was very high in grade seven when compared to other grade levels. Similarly, female students' dropout was increased to the second highest rate. In harmony with this finding, data received via interview and focus group discussion have shown that the reason why students leave their school at upper primary school level is that they serve their family at home and earn their own income in order to continue the school. On the other hand, the rates of male and female students were reduced at grade eight by high amount of rate, i.e. $10.43 \%$ and while their counter parts rate was slightly reduced to $14 \%$.

Generally, when we see dropout rate in terms of gender male students dropped out of the school than females (male $16.02 \%$ and female $12.24 \%$ ).

As shown in Figure 2, out of four schools of Sawena woreda, the highest dropout rate was found in Beleso primary school with the rate of $28.31 \%$ followed by Arda Gelma $20.06 \%$, Cophi $16.01 \%$. The school with lowest dropout rate when compared to the rest three schools was Malka Dare primary school (10.77\%). Likewise, from Delo Mena woreda primary schools, the highest dropout rate was found in Deyu primary school (19.8\%). Whereas the second, third and lowest dropout rate was found in Haya Oda, Meslo and Kele Golba primary schools respectively. With regards to the dropout rate of Berisa, Waduma, Bidire and Mada primary schools of Madda Walabu Woreda from highest to lowest was 12.68\%, 10.93\%, 10.92\% and 9.5\% respectively. Among primary schools in Rayitu Woreda, Egu primary school was found to be the highest dropout rate, which accounts for $15.33 \%$. Whereas Gurura, Arada Kalo, and Adala primary schools dropout rate was the second (13.03\%), third (8.5\%) and fourth $(7.75 \%)$ respectively.

The schools which have food program attracted students to school. For instance, Mada primary school principal reported that "before this academic year 2013/14, there was food program in our school. Students eat food at school even though they are tired while walking to school. However in this year, the food program is not 
available for the school for unknown reason. This became one of the great reasons for dropout." In the same manner, Sawena woreda education office head support the argument. He argued that there are nine schools which have food program in the woreda. According to him, besides food, every girl students take one gallon of oil. Therefore, girl students are actively participating on education and the ratio of girl students is found to be one to one.

As it can be observed from Figure 3, the overall dropout rate by woredas, from left to right Delo Mena, Madda Walabu, Rayitu and Sawena woredas were $12.76 \%, 11.00 \%, 11.15 \%$ and $18.79 \%$ respectively. The result suggested that the dropout rate was high in Sawena woreda when compared to the three woredas. To sum up, the overall, dropout rate of four woredas were $13 \%$.

\section{Discussion}

The results shows that the prevalence was vary from grade to grade. For instance, in this study the highest dropout rate was found in grade seven for males $28.57 \%$. The second highest dropout rate was seen in grade one for male. On the other hand, the rates of male students were decreased at grade eight by high amount of rate, i.e.

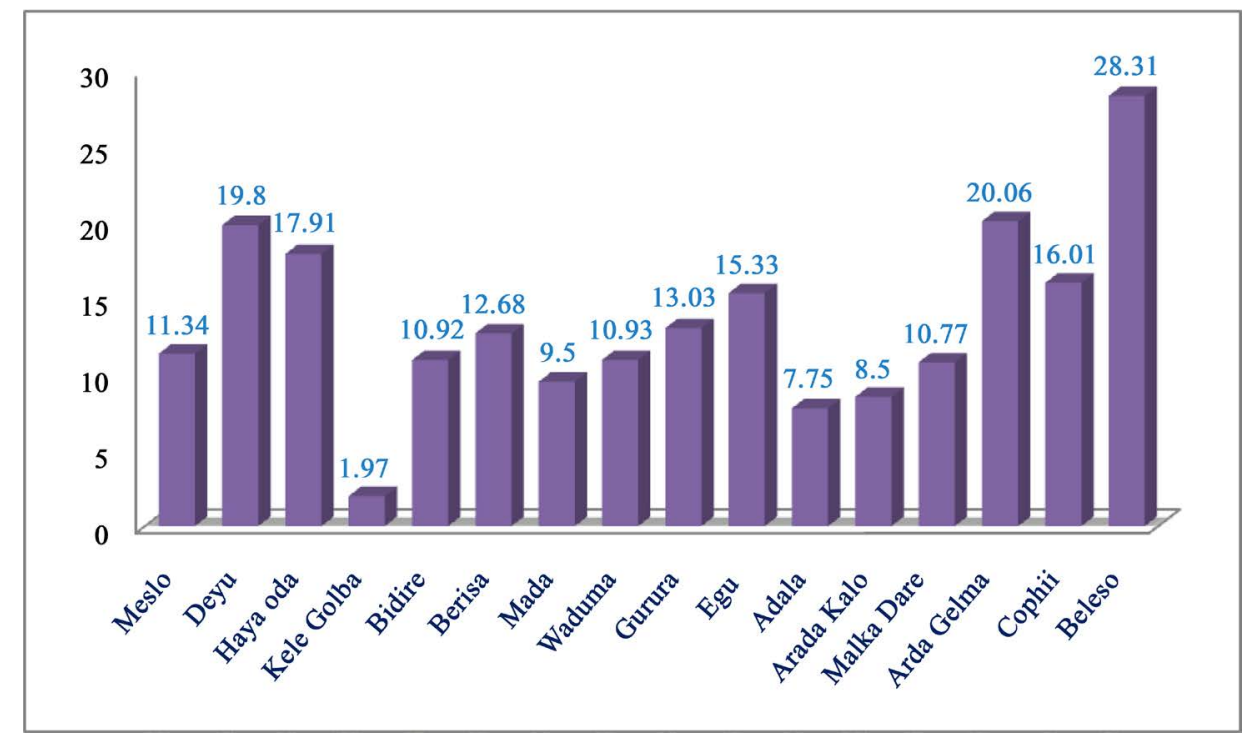

Figure 2. Prevalence of primary school dropout rate of 2013/14 by school in percent.

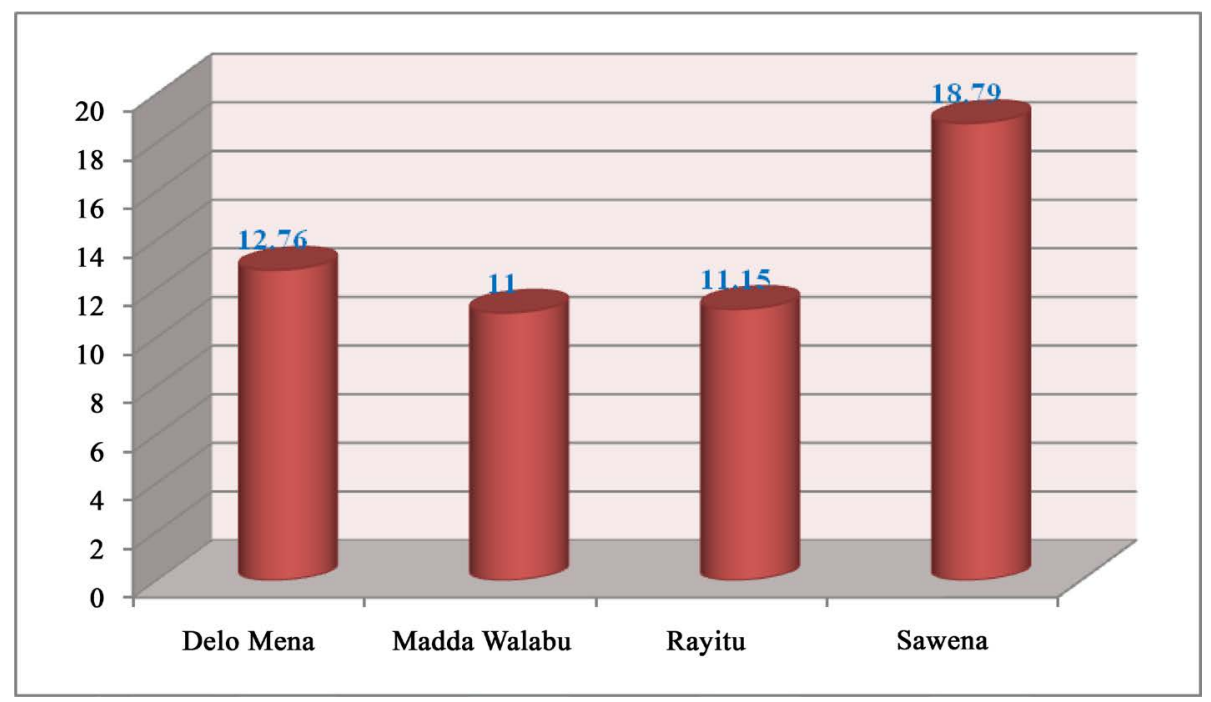

Figure 3. Prevalence of primary school dropout rate of 2013/14 by woredas in percent. 
$10.43 \%$. Whereas the highest rate was observed in grade five for females $18.07 \%$ and the rate was also high in grade seven that is the second rate. The qualitative data suggests that this is due to female students' engagement in marriage at this age. When compared to other grade levels the lowest dropout rate was found in grade six for female students. But the qualitative finding suggests that students' schooling dropping increase as the grade level increases. The report of Ethiopian ministry of education shows that the rate is vary from grade to grade for instance, from first primary cycle the rate is high in grade one, whereas from second primary cycle significant number of dropout was found in grade five and grade eight. On the other hand, the lowest dropout rate was registered at grade three [8]. Similarly, this study found that grade one students leave their school due to that they are too child to walk to school long distance on foot and these children always move from place to place with their family while their family migrate from one place to other due to the mobile nature of pastoralists.

The overall, dropout rate of four woredas' were $13 \%$. Even if this figure is less than the dropout rate of Oromia regional state (18.6\%) at regional level [7], it is much bigger than the rate of Bale zone pastoral primary schools which is $5.62 \%$ [11]. More specifically, of the four woredas of the study area the rate of school dropout was high in Sawena Woreda when compared to the rest three. In addition to this, the current finding revealed that dropout rate of male students was greater than that of female students (male $16.02 \%$ and female $12.24 \%$ ). This finding consistent with [6] found that $19 \%$ of boys dropped out of school than girls $16.8 \%$ at Bale Zone primary schools.

While collecting data, the researchers were faced a challenge in getting full members of Kebele Education and Training Board in some schools. This is due to the livelihood nature of pastoral communities. Thus, it is good idea if potential researcher who wants to conduct study on this area take ample time, live like the local communities and manage the issues that could be emanated from different sources therefore he/she come up with more inclusive findings.

\section{Conclusion}

The main objective of this was to assess the prevalence of primary school dropout in the case of pastoral woreads in Bale Zone of Oromia Regional state, Southeastern Ethiopia. The current dropout rate is high 13\%. The rate was high in grade seven for boys and in grade five for girls. In the schools which have food support the rate was low and vice versa. Out of the four woredas in Sewena the rate was high. Hence, all internal stakeholders of education such as woredas and zonal education office, Oromia education bureau, Oromia Pastoral Development Commission and federal ministry of education should work together via developing strategies how to reduce primary school dropout after assessing the major determinants of the problem.

\section{Acknowledgements}

We would like to thank Madda Walabu University for financial support to conduct this research. Our heartfelt thanks also extend to all participants of this study for their willingness and participation in this study; without your contributions we would not have completed this study.

Lastly but not least, we would like to thank many close friends from Madda Walabu University and working in other institutions who initiated us and edited the manuscript with all heartily once again we thank you keep in touch.

\section{References}

[1] UNICEF (2012) All Children in School by 2015: Global Initiative on Out-Of-School Children Ghana Country Study: UNICEF, Accra.

[2] Mphale, L.M. (2014) Prevalent Dropout: A Challenge on the Roles of School Management Teams to Enhance Students Retention in Botswana Junior Secondary Schools. International Journal of Business and Social Science, 5, 178-188.

[3] Hanusbek, E.A. (1995) Interpreting Recent Research on Schooling in Developing Countries. The World Bank Research Observer, 10, 227-246. http://dx.doi.org/10.1093/wbro/10.2.227

[4] USAID (2005) Oromia Regional State Perspective Plan for Universal Primary Education. Addis Ababa, Oromia Education Bureau.

[5] Tassew, W., Jones, N. and Bekele, T. (2006) Children's Educational Completion Rates and Dropouts in the Context of Ethiopia's National Poverty Reduction Strategy. Contributed Paper Prepared for Presentation at the International Association of Agricultural Economists Conference, Gold Coast. 
[6] Oromia Education Bureau (2014) Education Statistics Annual Abstract 2012/2013 (2005 E.C.). SIVANET Printing, Finfine.

[7] MOE (2013) Education Statistics Annual Abstract 2012/2013 (2005 E.C.). Ministry of Education, Addis Ababa.

[8] Tassew, W. (2013) Shocks and Children’s Dropout from Primary School: Implications for Education Policy in Ethiopia. 12th UKFIET International Conference of Education and Development Oxford, 10-12 September 2013.

[9] Tassew, W. and Adiam, H. (2012) Shocks and Primary School Drop-out Rates: A Study of 20 Sentinel Sites in Ethiopia. Young Lives, London.

[10] Biyabeyen, M. and Tadesse, H. (2015) The Root Cause Factors and the Status of Students Drop-out in Public Primary Schools of Harari Regional State, Ethiopia. Middle Eastern \& African Journal of Educational Research, Issue 15, 1629.

[11] Bale Zone Education Office (2013) Primary School Students Dropout in Bale Zone Pastoralists. Annual Report of 2012/13. Robe.

[12] Teshome N. (2002) Low Participation of Female Students in Primary Education: A Case Study of Dropouts from the Amhara and Oromia Regional States in Ethiopia. UNESCO International Institute for Capacity Building in Africa, Addis Ababa. 